Check for updates

Cite this: RSC Adv., 2018, 8, 7330

Received 23rd November 2017 Accepted 8th February 2018

DOI: 10.1039/c7ra12701d

rsc.li/rsc-advances

\section{Porous metalloporphyrinic nanospheres constructed from metal 5,10,15,20-tetraksi(4' - ethynylphenyl)porphyrin for efficient catalytic degradation of organic dyes $\dagger$}

\begin{abstract}
Yongjin Li, Liming Wang, Yong Gao, Weijun Yang, (DD* Yingying Li and Cancheng Guo
Novel conjugated metalloporphyrin polymers (PP-EPMn and PX-EPMn) were synthesized by the Sonogashira coupling reaction with $M n(I I I) 5,10,15,20$-tetraksi(4'-ethynylphenyl)porphyrin ([pethynyl $]_{4} \mathrm{PMn}$ ) as building block, and with phenylene and xenyl groups as bridges, respectively. Fine nanospheres were obtained through control of the reaction conditions. The two polymer nanospheres were characterized in detailed by BET, FE-SEM, HR-TEM, FT-IR, UV-Vis and XPS, revealing that they were highly ordered, highly developed microporous and super-conjugated metalloporphyrin polymers with large surface areas and uniform pore sizes. Their electrochemical behaviors and hydrophilicity were also investigated. With the synergistic effects of porous nanosphere structure and conjugated covalent structure, PP-EPMn and PX-EPMn showed excellent catalytic activity and reusability in the catalytic degradation of methylene blue (3,7-bis(dimethylamino)-5-phenothiazinium chloride) in aqueous solution. The good hydrophilicity of the polymer nanospheres promoted the catalytic degradation. In particular, unlike Fenton degradation systems that require acidic conditions, PP-EPMn degraded methylene blue significantly better under alkaline conditions, which implied a good prospect in treating industrial methylene blue dye wastewater.
\end{abstract}

\section{Introduction}

Porphyrin and its derivatives, as an important class of biological compounds in the nature, have been widely used in solar cells, biosensors, catalytic reactions and gas adsorption due to their characteristic ring structures of conjugated double bonds. ${ }^{1-6}$ In recent years, metalloporphyrins have been employed as biomimetic catalysts in a variety of oxidation reactions such as the degradation of organic dyes., ${ }^{7,8}$ But in fact, monomer metalloporphyrins have limitations in practice application..$^{9-11}$ For example, some water-soluble metalloporphyrins with peripheral groups $\left(\mathrm{COOH}, \mathrm{N}\left(\mathrm{CH}_{3}\right)_{3}, \mathrm{SO}_{3}\right)$ have been used to treat organic dyes in water. However, they cannot be recycled as they are hard to separate from reaction solutions. ${ }^{\mathbf{1 2 - 1 5}}$ Some other metalloporphyrins, although with high catalytic oxidation activities, cannot dissolve in water, which limits the catalytic performance in aqueous solution, especially in the degradation of water-soluble organic dyes. Some new immobilized monomer metalloporphyrin composites with outstanding catalytic performances in aqueous solution, such as carbon-nanotube-porphyrin, $\mathrm{C}_{60^{-}}$

College of Chemistry and Chemical Engineering, Hunan University, Changsha 410082, Hunan, China. E-mail: wjyang@hnu.edu.cn

$\dagger$ Electronic supplementary information (ESI) available. See DOI: $10.1039 / \mathrm{c} 7 \mathrm{ra} 12701 \mathrm{~d}$ porphyrin, graphene oxide-porphyrin and $\mathrm{TiO}_{2}$-porphyrin composites, have been synthesized. ${ }^{16-25}$ However, the bonds between porphyrins and solid support surfaces are unstable, so the activities of supported metalloporphyrins decline soon in reuse.

Conjugated microporous and mesoporous polymers (CMPs) are a new type of covalent polymers with novel structures as well as high thermostability and porosity, some of which exhibit superb catalytic performances in non-polar reactions. ${ }^{26-29}$ However, it is difficult to synthesize CMPs constructed from metalloporphyrins as building blocks, as we all know that porphyrin rings are hard to be polymerized directly by covalent linkages because of the bulky steric hindrance between porphyrin molecules. Therefore, metalloporphyrin CMPs have rarely been reported. ${ }^{30-32}$ Based on the disadvantages of metalloporphyrins and their immobilized composites in aqueous reaction and the advantages of metalloporphyrin CMPs for catalysis, we are interested in whether we can synthesize conjugated micro- and mesoporous polymers with monomer metalloporphyrins as building blocks to apply them in the catalytic degradation of water-soluble organic dyes. Since it is rather difficult to control the morphology of porphyrin polymers, most currently available conjugated polymers have sheet structures. In this study, the morphology of metalloporphyrin CMPs was regulated by selecting appropriate reaction conditions, metalloporphyrin templates and bridging groups. 
Mn(III)5,10,15,20-Tetraksi(4'-ethynylphenyl)porphyrin $\quad$ ([pethynyl $]_{4} \mathrm{PMn}$ ) can connect another small organic molecule through its terminal alkyne on the para-way. ${ }^{33,34}$ So we chose small organic molecule 1,4-dibromobenzene and 4,4'-dibromobiphenyl as the precursor bridges. The formation of xenyl or phenylene between porphyrin molecules can weaken the steric hindrance, and the rotation of alkynyl group and rigidity of xenyl and phenylene groups can modulate the morphology of polymer products during polymerization. So we try to synthesize two kinds of organic conjugated porphyrin polymers with nanosphere features, PP-EPMn and PX-EPMn, which were bridged by phenylene and xenyl groups respectively. Methylene blue is a typical organic dye in waste water and has usually been selected as a model of hard-degradable organic dyes. So with methylene blue as degradation model, the catalytic performance of the two polymers was studied under mild conditions in this work, and excellent results were produced.

\section{Experimental section}

\subsection{Materials and characterizations}

Bromobenzaldehyde (99.77\%, Aladdin Reagents (Shanghai) Co., Ltd.), palladium acetate $(47.5 \% \mathrm{Pd})$, triphenylphosphine, copper iodide, $\mathrm{H}_{2} \mathrm{O}_{2}(30 \%)$, pyrrole (redistilled before use) and other reagents were all analytical grades and purchased from J\&K Chemicals. THF was distilled over sodium and benzophenone ketyl under argon before use. [p-Ethynyl $]_{4} \mathrm{PMn}$ was synthesized according to documented procedures and characterized by IR, UV-Vis, ${ }^{1} \mathrm{H}-\mathrm{NMR}$ and MS spectroscopies $(\mathrm{ESI} \dagger) .^{35}$

\subsection{Synthesis of alkynylporphyrin conjugated organic polymers PP-EPMn and PX-EPMn}

The steps of synthesizing PP-EPMn by 1,4-dibromobenzene were as follows:

A mixture of [p-ethynyl $]_{4} \mathrm{PMn}(80.0 \mathrm{mg}, 0.1 \mathrm{mmol}), 1,4$ dibromobenzene (56.64 $\mathrm{mg}, 0.24 \mathrm{mmol})$, triphenylphosphine (105.0 mg, $0.4 \mathrm{mmol}$ ), palladium acetate $(22.4 \mathrm{mg}, 0.1 \mathrm{mmol})$ and copper iodide (38.1 mg, $0.2 \mathrm{mmol}$ ) was added into a $100 \mathrm{~mL}$ three-necked flask, and air was degassed by three cycles of argon gas pumping-inflation. Air-removed THF $(6 \mathrm{~mL})$ and triethylamine $(4 \mathrm{~mL})$ were then injected into the three-necked flask under stirring and refluxed at $76{ }^{\circ} \mathrm{C}$ for two hours. Finally, the mixture was poured into plenty of aqueous KI solution after being cooled to room temperature. The solid crude product was then collected by filtration, and carefully washed with water, THF, methanol and trichloromethane in turn. It was also washed by Soxhlet extraction with water, THF, methanol and trichloromethane for $24 \mathrm{~h}$, respectively, and then dried in vacuum, giving a dark green solid (PP-EPMn) with a yield of $88.9 \%$ (Scheme 1 ).

PX-EPMn was synthesized by using $4,4^{\prime}$-dibromobiphenyl as bridge. The steps were similar to those for PP-EPMn, but the reaction time must be extended to three hours, with the yield of only $70.0 \%$.

\subsection{Degradation of methylene blue}

Aqueous methylene blue solution $\left(10 \mathrm{mg} \mathrm{L}^{-1}, 50 \mathrm{~mL}\right)$ was put in a flask, after $\mathrm{pH}$ adjustment, the reaction was carried out at room temperature $\left(25^{\circ} \mathrm{C}\right)$ with magnetic stirring when a certain

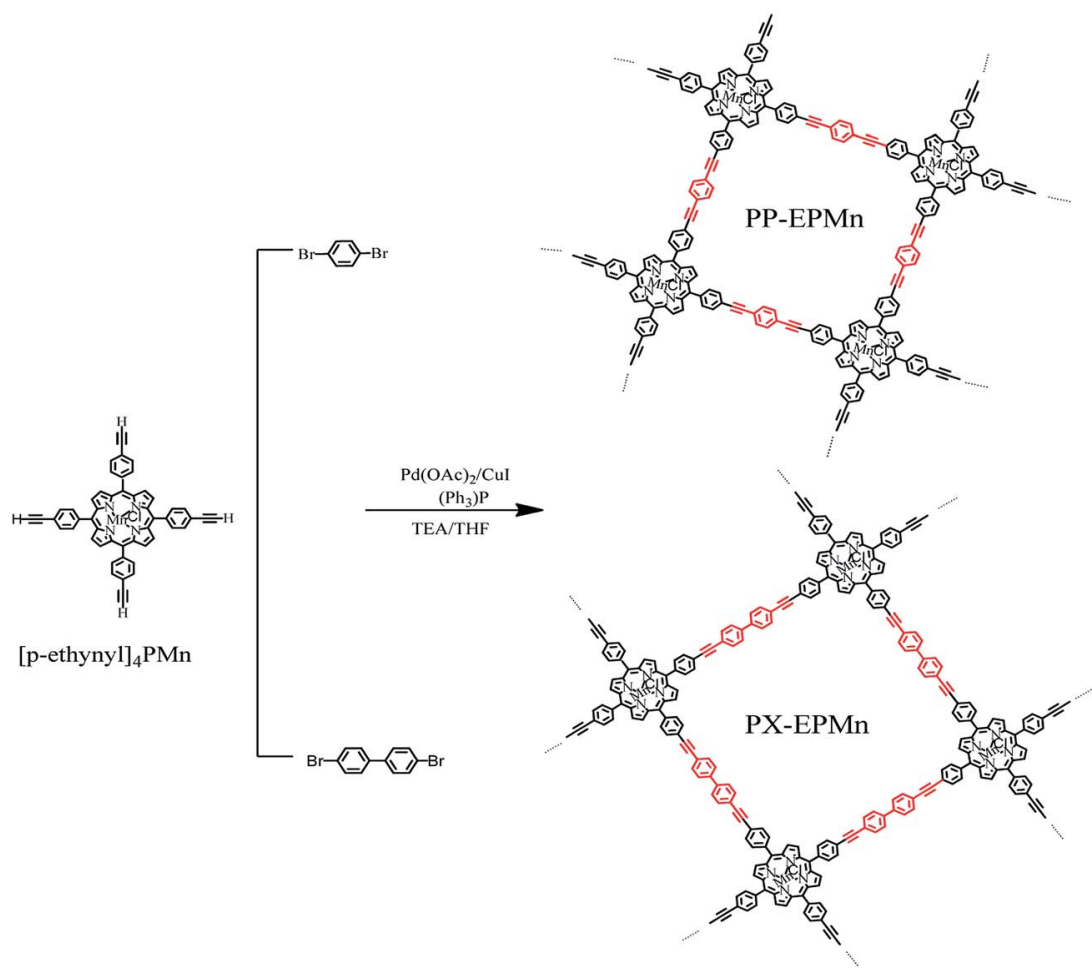

Scheme 1 Synthesis of nanoporous polymer PP-EPMn and PX-EPMn. 
amount of PP-EPMn or PX-EPMn and $\mathrm{H}_{2} \mathrm{O}_{2}$ solution were added into the flask. The mixture was sampled at fixed time intervals and rapidly centrifuged, from which the supernatants were collected and tested by UV-Vis spectroscopy. The absorbance of the characteristic absorption peak at $664 \mathrm{~nm}$ was measured to calculate the corresponding reduction rate of methylene blue.

\section{Results and discussion}

\subsection{Characterizations of PP-EPMn and PX-EPMn}

As shown in Fig. 1, the IR spectra of PP-EPMn (b) and PX-EPMn (c) are obviously different from that of [p-ethynyl $]_{4} \mathrm{PMn}$ (a), suggesting that the polymerization reaction occurred indeed. The peak at $3293 \mathrm{~cm}^{-1}$ in the spectrum of [p-ethynyl ${ }_{4} \mathrm{PMn}$ is assigned to $\mathrm{C}-\mathrm{H}$ stretching of $-\mathrm{C} \equiv \mathrm{C}-\mathrm{H}$, which disappears after formation of PP-EPMn and PX-EPMn due to the consumption of $\mathrm{C}-\mathrm{H}$. The characteristic peak of $-\mathrm{C} \equiv \mathrm{C}-$ at $2101 \mathrm{~cm}^{-1}$ attenuates and even disappears because the structures of PP-EPMn and PX-EPMn are highly symmetric. Meanwhile, the peak bathochromically shifts to $2200 \mathrm{~cm}^{-1}$. Besides, the peak at $3048 \mathrm{~cm}^{-1}$ belonging to $\mathrm{C}-\mathrm{H}$ stretching vibration of phenylene and xenyl is strengthened, which means there are phenylene and xenyl in PP-EPMn and PX-EPMn. On the other hand, the IR spectra of PP-EPMn and PX-EPMn exhibit a characteristic N-Mn vibration band at $1009 \mathrm{~cm}^{-1}$, which is the same as that of [p-ethynyl] $]_{4} \mathrm{PMn}\left(1007 \mathrm{~cm}^{-1}\right)$. The bands at $1599 \mathrm{~cm}^{-1}$ correspond to $\mathrm{C}=\mathrm{C}$ stretching in phenyls, and that at $1493 \mathrm{~cm}^{-1}$ represents $\mathrm{C}=\mathrm{C}$ stretching in porphyrin. Thus, [p-ethynyl $]_{4} \mathrm{PMn}$ had already been introduced into the porous structures of PPEPMn and PX-EPMn in which manganese ion was still stably coordinated.

The UV-Vis spectra of PP-EPMn and PX-EPMn solid powders and that of [p-ethynyl $]_{4} \mathrm{PMn}$ in $\mathrm{CHCl}_{3}$ solution are exhibited in Fig. 2. In curve (a), a strong absorption band at $481 \mathrm{~nm}$ is the Soret band of [p-ethynyl $]_{4} \mathrm{PMn}$, and those at 582 and $621 \mathrm{~nm}$ are the Q-bands. PP-EPMn and PX-EPMn (curves b, c) also show similar typical UV-Vis spectra to that of [p-ethynyl $]_{4} \mathrm{PMn}$, i.e.

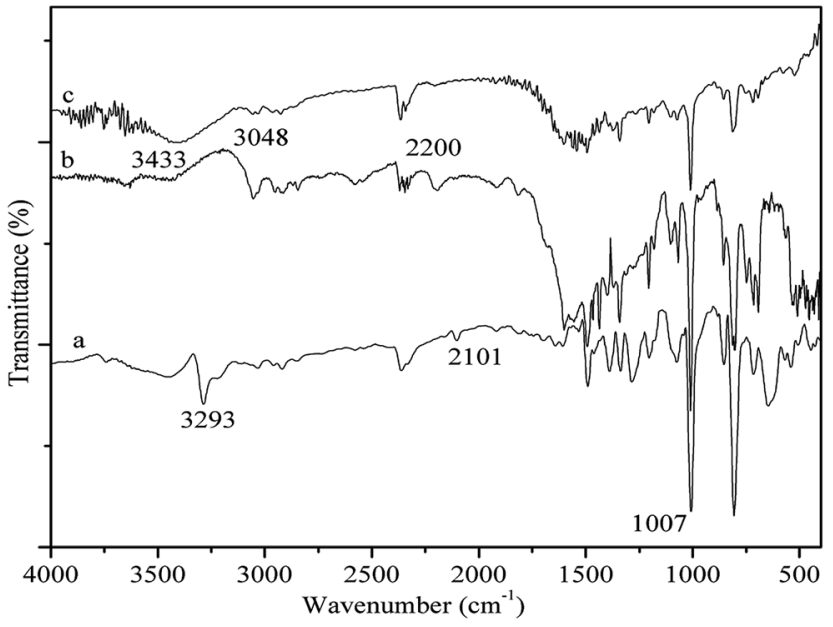

Fig. 1 FT-IR spectra of [p-ethynyl] $]_{4} P M n(a), P P-E P M n(b)$ and PXEPMn (c).

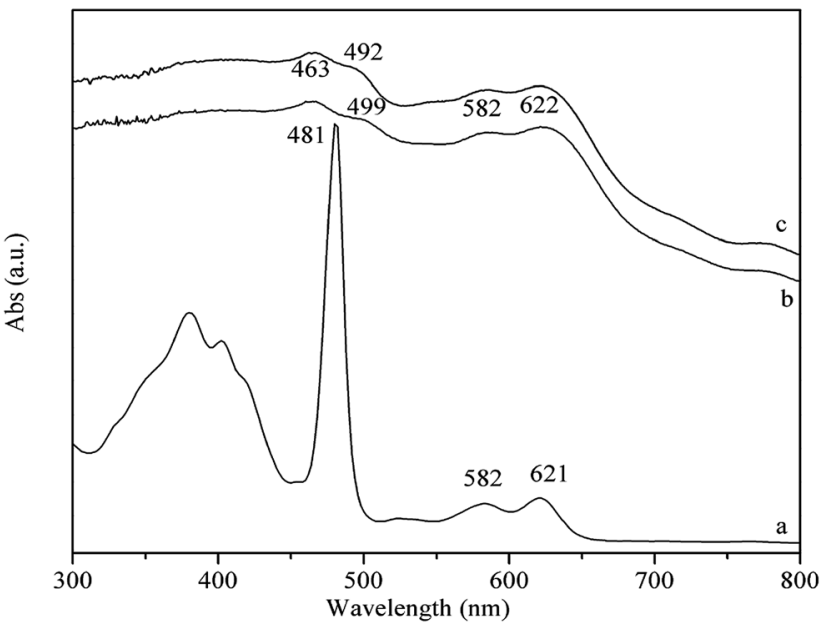

Fig. 2 UV-Vis spectra of [p-ethynyl] ${ }_{4} \mathrm{PMn}$ (a; $\mathrm{CHCl}_{3}$ solution), PPEPMn (b; powder sample), and PX-EPMn (c; powder sample).

there are Soret bands at 463, $499 \mathrm{~nm}$ and Q-bands at 582, $622 \mathrm{~nm}$ in PP-EPMn, and Soret bands at 463, $492 \mathrm{~nm}$ and Qbands at 582, $622 \mathrm{~nm}$ in PX-EPMn. Compared with [pethynyl $]_{4}$ PMn monomer, the Soret band in PP-EPMn splits into 463, $499 \mathrm{~nm}$ and that in PX-EPMn splits into 463, $492 \mathrm{~nm}$ because of the conjugated bridges increasing the molecular connectivity and the electronic couplings of polymers.

PP-EPMn and PX-EPMn were conjugated metalloporphyrin polymers with large BET surface areas and porous structures. At $77 \mathrm{~K}$, they displayed typical type-III nitrogen sorption isotherm curves along with strong adsorptions at low pressure $\left(P / P_{0}<0.1\right)$ (Fig. 3), suggesting micropores and mesopores coexisted in the framework. The BET surface area of PP-EPMn was as high as 420 $\mathrm{m}^{2} \mathrm{~g}^{-1}$, of which the microporous area (about $194 \mathrm{~m}^{2} \mathrm{~g}^{-1}$ ) accounted for $46.2 \%$. Meanwhile, the BET surface area of PXEPMn was $480 \mathrm{~m}^{2} \mathrm{~g}^{-1}$, of which the microporous area (about $204 \mathrm{~m}^{2} \mathrm{~g}^{-1}$ ) accounted for $42.5 \%$ (Table 1). Fig. 3 also shows that there are a large number of micropores in PP-EPMn and PX-EPMn frameworks. The main pore diameters of PP-EPMn and PX-EPMn were about $1.48 \mathrm{~nm}$ and $1.37 \mathrm{~nm}$ respectively, and the contributions to pore volume were $44.76 \%$ and $41.52 \%$ respectively. The pore structures of PP-EPMn and PX-EPMn also verified porphyrin polymerization. The pore diameter of PPEPMn slightly exceeded that of PX-EPMn because the bridge of phenylene was not strictly coplanar with porphyrin ring during polymerization, leading to distortion and interpenetration between the polymer mesh and chain and forming micropores. The non-coplanarity between xenyl and porphyrin ring was stronger than that between phenylene and porphyrin ring, so PX-EPMn had more obvious distortion and interpenetration as well as smaller pore diameter than those of PP-EPMn. Moreover, due to the larger molecular size of xenyl than that of phenylene, the pore size distribution of PX-EPMn was more decentralized than that of PP-EPMn.

FE-SEM images (Fig. 4a and b) show that PP-EPMn and PXEPMn are composed of nanosized round spheres. The diameters of PP-EPMn nanospheres ranged from $200 \mathrm{~nm}$ to $400 \mathrm{~nm}$, 


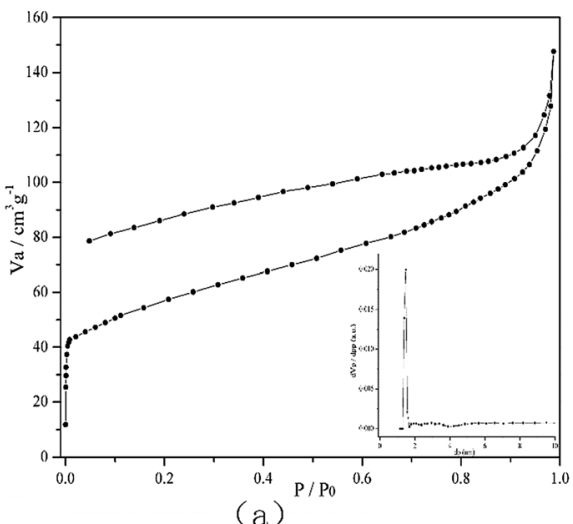

(a)

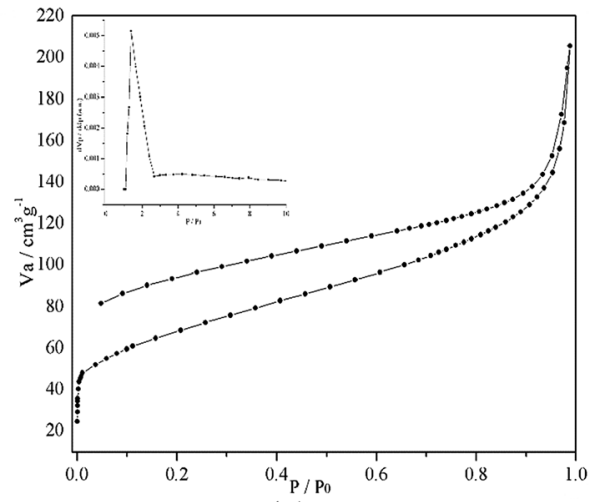

(b)

Fig. 3 Nitrogen adsorption and desorption isotherm profiles and pore diameter examination of PP-EPMn (a) and PX-EPMn (b) at 77 K.

Table 1 Surface properties of PP-EPMn and PX-EPMn ${ }^{a}$

\begin{tabular}{lllll}
\hline & $\begin{array}{l}S_{\text {BET }} \\
\left(\mathrm{m}^{2} \mathrm{~g}^{-1}\right)\end{array}$ & $\begin{array}{l}S_{\text {micro }} \\
\left(\mathrm{m}^{2} \mathrm{~g}^{-1}\right)\end{array}$ & $\begin{array}{l}V_{\text {total }} \\
\left(\mathrm{cm}^{3} \mathrm{~g}^{-1}\right)\end{array}$ & $\begin{array}{l}V_{\text {micro }} \\
\left(\mathrm{cm}^{3} \mathrm{~g}^{-1}\right)\end{array}$ \\
\hline PP-EPMn & & & & \\
PX-EPMn & 420 & 194 & 0.42 & 0.188 \\
{$[\text { p-Ethynyl }]_{4}$ PMn } & 480 & 204 & 0.619 & 0.257 \\
& 16.2 & 2.0 & $2.0 \times 10^{-4}$ & -
\end{tabular}

${ }^{a} S_{\mathrm{BET}}$ : total surface area; $S_{\text {micro }}$ : micropore surface area; $V_{\text {total }}$ : total pore volume; $V_{\text {micro }}$ : micropore volume.

whereas those of PX-EPMn nanospheres with a more uniform diameter were mostly $150 \mathrm{~nm}$. The diameter of PP-EPMn nanospheres was slightly larger than that of PX-EPMn, corresponding to the higher distortion degree of polymer mesh and chain during polymerization. Therefore, with increasing distortion degree, PX-EPMn became more compact during polymerization, forming nanospheres with smaller diameters. TEM images (Fig. 4c and e) clearly demonstrate spherical structures of the materials, and the sizes of spheres are the same as those observed by SEM. The surface of PX-EPMn was much rougher than that of PP-EPMn because the spheres surface of PP-EPMn was will-proportioned, and PX-EPMn was more uneven. TEM revealed that PP-EPMn nanospheres had smooth edges but PX-EPMn ones had obvious light and dark areas. In addition, HE-TEM images (Fig. $4 \mathrm{~d}$ and f) present that PP-EPMn and PX-EPMn have the same nanoporous structures, but the porous channel of the former is slightly larger.

Cyclic voltammograms show that the first reduction potentials of PP-EPMn and PX-EPMn significantly shift to more positive values compared with that of [p-ethynyl $]_{4} \mathrm{PMn}$ (from $-0.18 \mathrm{~V}$ to $0.13 \mathrm{~V}$ and $0.15 \mathrm{~V}$ respectively, Fig. 5), indicating that porphyrin monomers were bridged by phenylene and xenyl groups on the four directions of porphyrin rings. Over $310 \mathrm{mV}$ decrease in the reduction potential can be attributed to the good electron transfer properties of porphyrin networks in PPEPMn and PX-EPMn. As a conjugated bridge between porphyrin monomers, phenylene ethylene was advantageous to
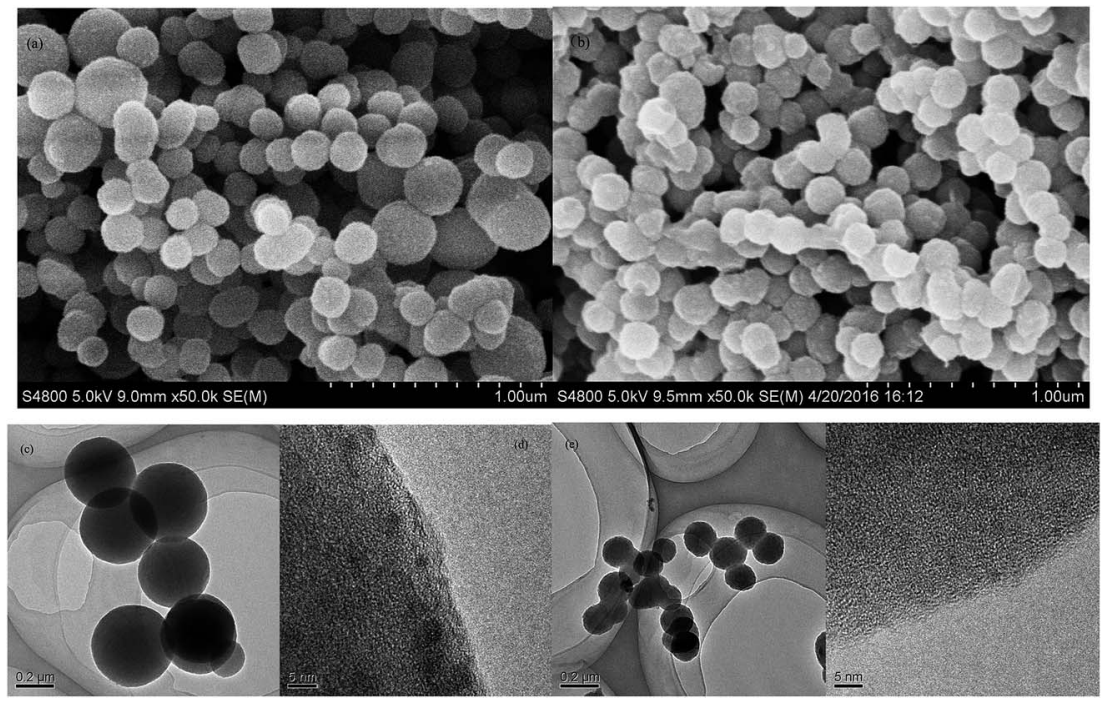

Fig. 4 FE-SEM images of PP-EPMn (a) and PX-EPMn (b). TEM images of PP-EPMn (c, d) and PX-EPMn (e, f). 


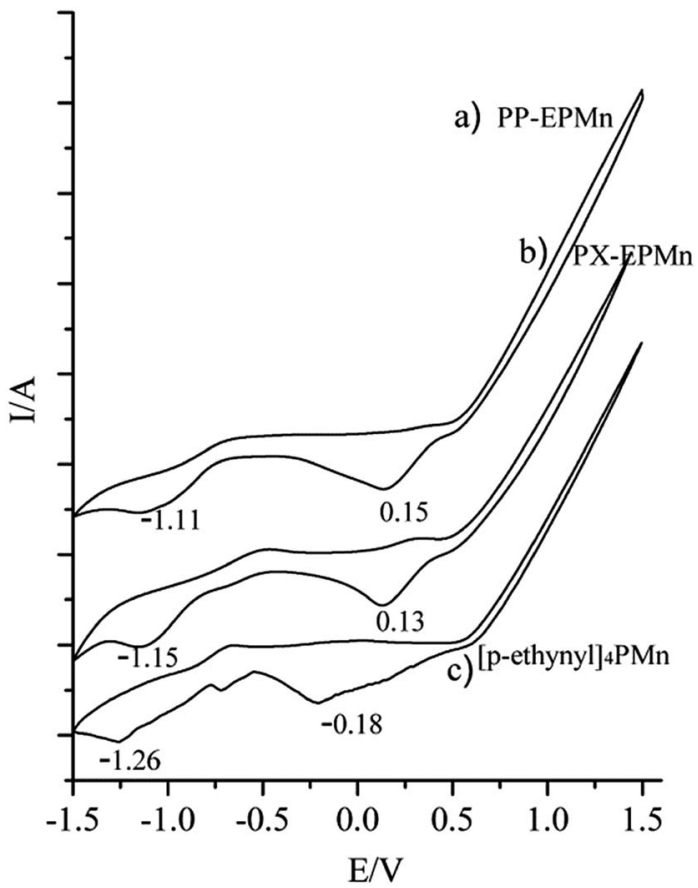

Fig. 5 Cyclic voltammetry curves of PP-EPMn (a), PX-EPMn (b) on the glass carbon electrodes in $0.1 \mathrm{~mol} \mathrm{~L}^{-1}\left(\mathrm{CH}_{3} \mathrm{CH}_{2}\right)_{4} \mathrm{NBr} \mathrm{CH}_{2} \mathrm{Cl}_{2}$ solution; cyclic voltammetry curves of [p-ethynyl] ${ }_{4} \mathrm{PMn}$ (c) in $\mathrm{CH}_{2} \mathrm{Cl}_{2}$, $0.1 \mathrm{~mol} \mathrm{~L}^{-1}\left(\mathrm{CH}_{3} \mathrm{CH}_{2}\right)_{4} \mathrm{NBr}$. Scan rate $50 \mathrm{mV} \mathrm{s}^{-1}$.

wide-range flow of electrons and delocalization. As a result, $\mathrm{Mn}^{3+}$ ions in the middle of porphyrin rings were further activated to form active valence ions $\mathrm{Mn}^{2+}$, which enhanced the catalytic activities of polymers in the oxidation reactions.

\subsection{Catalytic degradation of methylene blue}

To study the catalytic effects of PP-EPMn and PX-EPMn on methylene blue oxidizing degradation, comparative tests were carried out in the presence of hydrogen peroxide, porphyrin, polymers, porphyrin and hydrogen peroxide, or polymers and hydrogen peroxide, respectively. The results are summarized in Table 2, and the UV-Vis spectra of methylene blue after $3 \mathrm{~h}$ of catalytic oxidation with different catalysts are shown in Fig. 6.

Table 2 Efficiency of various catalysts in degradation of methylene blue $^{a}$

\begin{tabular}{llc}
\hline Entry & Catalyst & Degradation (\%) \\
\hline 1 & $\mathrm{H}_{2} \mathrm{O}_{2}$ & 12.5 \\
2 & {$[\mathrm{p} \text {-Ethynyl }]_{4} \mathrm{PMn}$} & 9.5 \\
3 & {$[\mathrm{p}-\text { Ethynyl] }]_{4} \mathrm{PMn}+$} & 15.5 \\
& $\mathrm{H}_{2} \mathrm{O}_{2}$ & \\
4 & PP-EPMn & 38.2 \\
5 & PP-EPMn $+\mathrm{H}_{2} \mathrm{O}_{2}$ & 99.6 \\
6 & PX-EPMn $+\mathrm{H}_{2} \mathrm{O}_{2}$ & 99.5
\end{tabular}

${ }^{a}$ Methylene blue, $50 \mathrm{~mL}\left(10 \mathrm{mg} \mathrm{L}^{-1}\right)$; catalyst, $4 \mathrm{mg} ; \mathrm{H}_{2} \mathrm{O}_{2}, 1 \mathrm{~mL} ; T=$ $25^{\circ} \mathrm{C} ; \mathrm{pH}=7$; time $=3 \mathrm{~h}$.

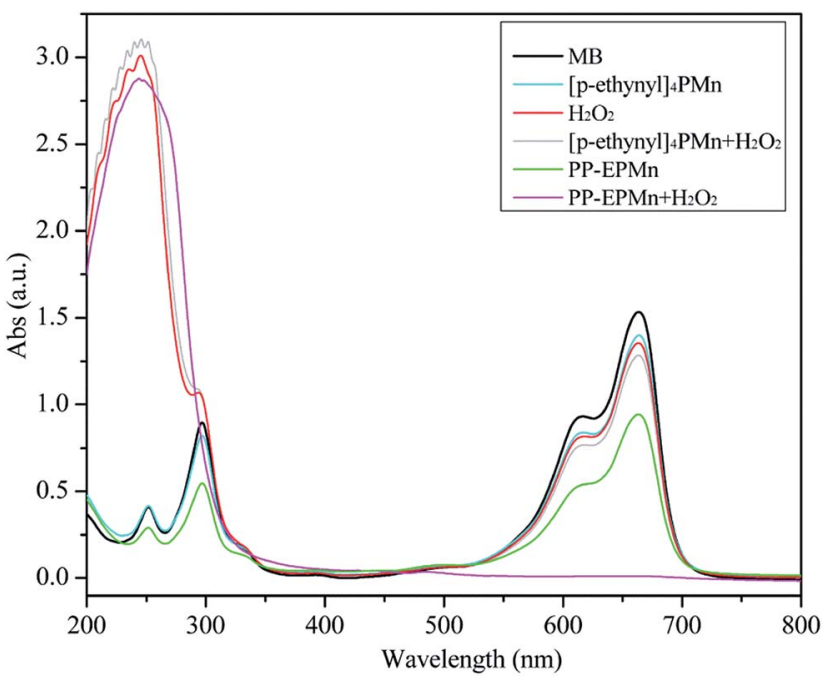

Fig. 6 UV-Vis spectroscopy of methylene blue after $3 \mathrm{~h}$ catalytic oxidation used different catalysts. Reaction conditions: methylene blue, $50 \mathrm{~mL}\left(10 \mathrm{mg} \mathrm{L}^{-1}\right)$; catalyst, $4 \mathrm{mg} ; \mathrm{H}_{2} \mathrm{O}_{2}, 1 \mathrm{~mL} ; T=25^{\circ} \mathrm{C} ; \mathrm{pH}=7$; time $=3 \mathrm{~h}$.

A small amount of methylene blue (12.5\%) was degraded only in the presence of hydrogen peroxide and without catalysts (Table 2). In the presence of [p-ethynyl $]_{4} \mathrm{PMn}$ or even coexisting hydrogen peroxide, the oxidation did not exceed $15.5 \%$, indicating that it failed to effectively degrade methylene blue. Additionally, 38.2\% of methylene blue was degraded by PP-EPMn in the absence of $\mathrm{H}_{2} \mathrm{O}_{2}$, which was markedly increased to $99.5 \%$ after $1 \mathrm{~mL}$ of $\mathrm{H}_{2} \mathrm{O}_{2}$ was added. This result is also apparent from Fig. 6 that the characteristic absorption peak of methylene blue at $664 \mathrm{~nm}$ disappears after reaction in the presence of $\mathrm{H}_{2} \mathrm{O}_{2}$ and PP-EPMn. We also detected the reaction mixture by ion chromatograph and $\mathrm{NO}_{3}{ }^{-}, \mathrm{SO}_{4}{ }^{2-}$ and $\mathrm{Cl}^{-}$were found. These suggest the complete degradation of methylene blue.

As shown in Fig. 7, unlike highly hydrophobic [p-ethynyl $]_{4^{-}}$ $\mathrm{PMn}$ which has a contract angle of $138^{\circ}$ on the deionized water interface, PP-EPMn and PX-EPMn have the contract angles of about $101^{\circ}$ and $110^{\circ}$ respectively, suggesting that they were more hydrophilic. The contract angle of PP-EPMn was close to the wettability limit of water $\left(90^{\circ}\right)$, allowing it to contact and to react with dye molecules in water more easily, and its degradation efficiency was higher. This is in accordance with the reports about hydrophobicity affecting the catalytic performance. $^{36}$ In fact, PP-EPMn dispersed more rapidly and uniformly in aqueous solution in the experimental process. Thus, owing to the synergistic effects of porous nanosphere structure, conjugated covalent structure and good wettability, the catalytic activities of PP-EPMn and PX-EPMn were improved tremendously in the degradation of methylene blue dye.

Water-soluble organic dyes are most difficult to deal with among all pollutants in wastewater, the degradation of which is significantly affected by $\mathrm{pH}$, so we evaluated the effects of $\mathrm{pH}$ on the catalytic degradation of methylene blue by PP-EPMn (Fig. 8 and 9).

As shown in Fig. 8, methylene blue is hardly degraded at $\mathrm{pH}<3$, but its degradation rate gradually increases with rising 
a)

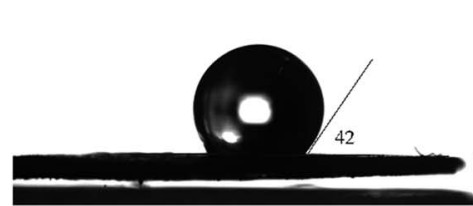

b)

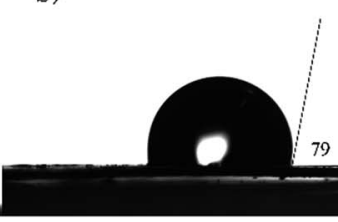

c)

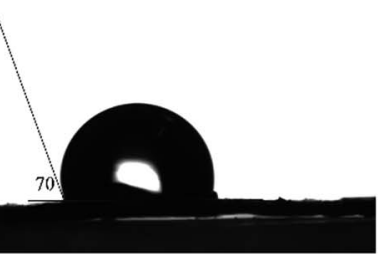

Fig. 7 Water contact angle of [p-ethynyl $]_{4} P M n(a), P P-E P M n(b)$ and PX-EPMn (c).
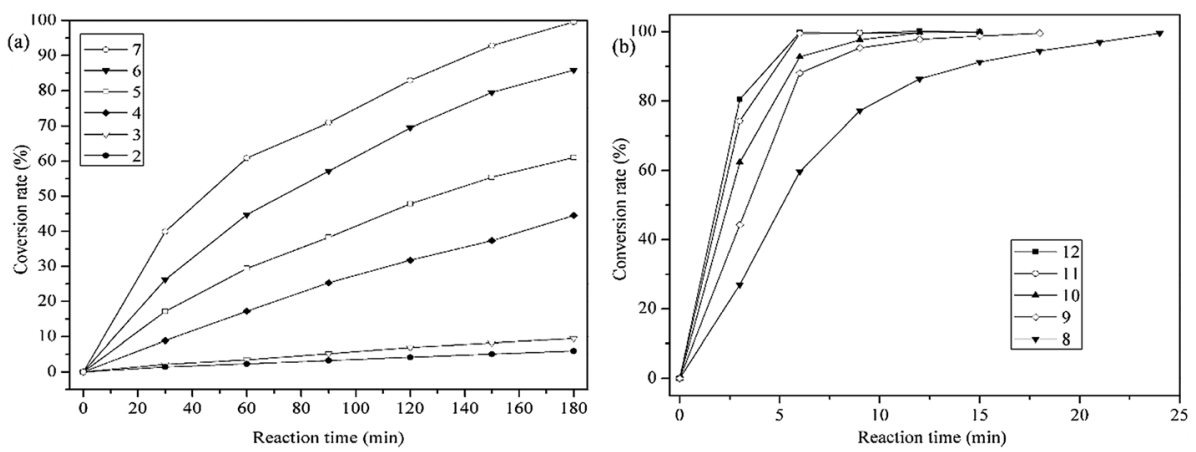

Fig. 8 Effects of $\mathrm{pH}$ on the catalytic oxidation. Reaction condition: methylene blue, $50 \mathrm{~mL}(10 \mathrm{mg} \mathrm{L}-1) ; \mathrm{catalyst}^{4} \mathrm{mg} \mathrm{H}_{2} \mathrm{O}_{2} ; \mathrm{T}=25{ }^{\circ} \mathrm{C}$.
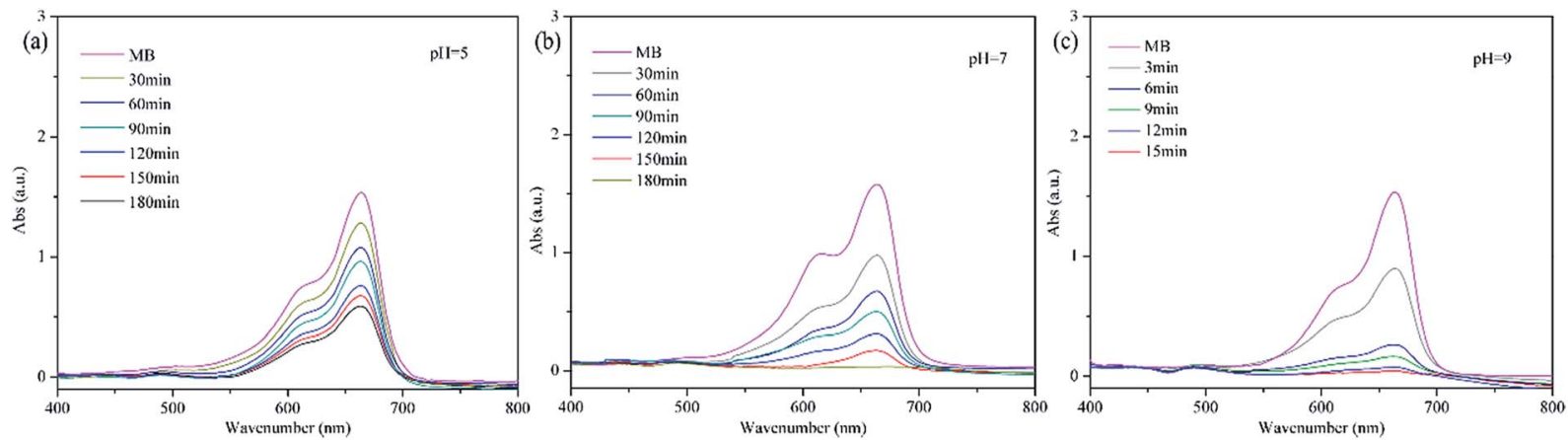

Fig. 9 Degradation of methylene blue by PP-EPMn at $\mathrm{pH}=5,7$, 9. Reaction condition: methylene blue, $50 \mathrm{~mL}^{(10} \mathrm{mg} \mathrm{L}^{-1}$ ); catalyst, $4 \mathrm{mg}$; $\mathrm{H}_{2} \mathrm{O}_{2}$; $T=25^{\circ} \mathrm{C}$.

$\mathrm{pH}$ within $3 \mathrm{~h}$. The degradation rate of methylene blue reached $59 \%$ at $\mathrm{pH}=5$ (Fig. 9a), increased significantly thereafter (Fig. 8a). Especially, the rate was $99.6 \%$ at $\mathrm{pH} 7$ after $3 \mathrm{~h}$ (Fig. 9b). Even more gratifying is that PP-EPMn degraded methylene blue better in alkaline solution (Fig. 8b), and the degradation rate remained above $99 \%$ with the reaction time greatly reduced. At $\mathrm{pH}=9$ (Fig. 9c), the degradation rate of methylene blue reached $87 \%$ in about $6 \mathrm{~min}$, and reached $99 \%$ within $12 \mathrm{~min}$. When $\mathrm{pH}$ was increased to 11 , the degradation rate reached $99 \%$ only within $6 \mathrm{~min}$. Oxomanganese(Iv) porphyrin complexes were generated by homolytic -O-Ocleavage of hydroperoxides by manganese(III) porphyrin polymer in acidic condition, which were less reactive intermediates than oxomanganese(v) porphyrin complexes that are generated by heterolytic -O-O- cleavage of hydro peroxides in alkaline condition. ${ }^{37}$ Hence, PP-EPMn degraded methylene blue better in alkaline condition than in acidic condition.
Actually, printing and dyeing plants generally generate alkaline wastewater. Since traditional Fenton reagents need acidic conditions to treat wastewater, considerable acids are consumed. In contrast, alkaline wastewater can be directly treated by PPEPMn. On the other hand, only wastewater at $\mathrm{pH}=6-9$ can be discharged into the environment, according to the national environmental standards. Given that PP-EPMn can function in alkaline wastewater which without cumbersome $\mathrm{pH}$ adjustment before being discharged into the environment, it is obviously superior to Fenton reagents. Therefore, PP-EPMn is a suitable catalyst for treating actual neutral or alkaline wastewater.

\subsection{Catalyst recyclability}

Metalloporphyrin was polymerized to special insoluble macromolecular polymers that converted metalloporphyrin catalytic system to heterogeneous catalysis. This is an important way to improve the stability and even catalytic activity of 
metalloporphyrin, making it easily recovered for recycling in reaction. Fig. 10 shows the percentages of methylene blue degradation catalyzed by PP-EPMn after each recovery cycle. Nearly $99 \%$ of methylene blue was reduced in each reaction cycle, suggesting that PP-EPMn remained stable and highly active after 5 runs in the system.

\subsection{XPS analysis}

As shown in Fig. 11a, a set of peaks corresponding to $\mathrm{Cl} 2 \mathrm{p}$ (197.8 eV), C 1s (284.8 eV), N 1s (398.9 eV), O 1s (532.2 eV) and Mn 2p (643.1 eV) are observed. [p-Ethynyl $]_{4}$ PMn (Fig. 11a, i), PPEPMn (Fig. 11a, ii) and used PP-EPMn (Fig. 11a, iii) had nearly the same chemical compositions. The ratios of the catalysts are shown in Table 3. Obviously, the proportions of atomic compositions of PP-EPMn and used PP-EPMn did not change which indicated that PP-EPMn was stable and the polymer structure was undamaged after five times of catalytic cycles. In the Mn 2p spectrum of [p-ethynyl $]_{4} \mathrm{PMn}$ (Fig. 11b), there were two main peaks, i.e. $\mathrm{Mn} 2 \mathrm{p}_{1 / 2}$ at $653.9 \mathrm{eV}$ and $\mathrm{Mn} 2 \mathrm{p}_{3 / 2}$ at $641.9 \mathrm{eV}$. The peak of $\mathrm{Mn} 2 \mathrm{p}_{3 / 2}$ can bed convoluted into two peaks, i.e. $641.7 \mathrm{eV}$ for $\mathrm{Mn}^{3+}$ and $642.8 \mathrm{eV}$ for $\mathrm{Mn}^{4+}$. As shown in Fig. 11d, used PP-EPMn also exhibits a $\mathrm{Mn}^{3+}$ peak at $641.7 \mathrm{eV}$ and $\mathrm{Mn}^{4+}$ peak at $642.8 \mathrm{eV}$. In the meantime, there is a peak of $\mathrm{Mn}^{2+}$ at $640.5 \mathrm{eV}$ and also a satellite peak at $648.1 \mathrm{eV}$, indicating that used PP-EPMn had $\mathrm{Mn}^{2+}$. This is the proof to the literature that $\mathrm{Mn}^{3+}$ should be reduced to $\mathrm{Mn}^{2+}$ at first in metalloporphyrin catalysis reactions. ${ }^{38}$ Besides, the $\mathrm{Mn} 2 \mathrm{p}_{3 / 2}$ peak of [p-ethynyl $]_{4^{-}}$ PMn (about $641.9 \mathrm{eV}$ ) shifted to $642.4 \mathrm{eV}$ in PP-EPMn after polymerization, which revealed that the redox property of PPEPMn was affected by the hyperconjugation structure in which electron cloud was delocalized from the center of $\mathrm{Mn}$ to the bridges and finally promoting the catalytic reaction. ${ }^{39}$

\subsection{Reaction kinetics}

The reaction kinetics of methylene blue oxidized by hydrogen peroxide with PP-EPMn as catalyst was also investigated. The

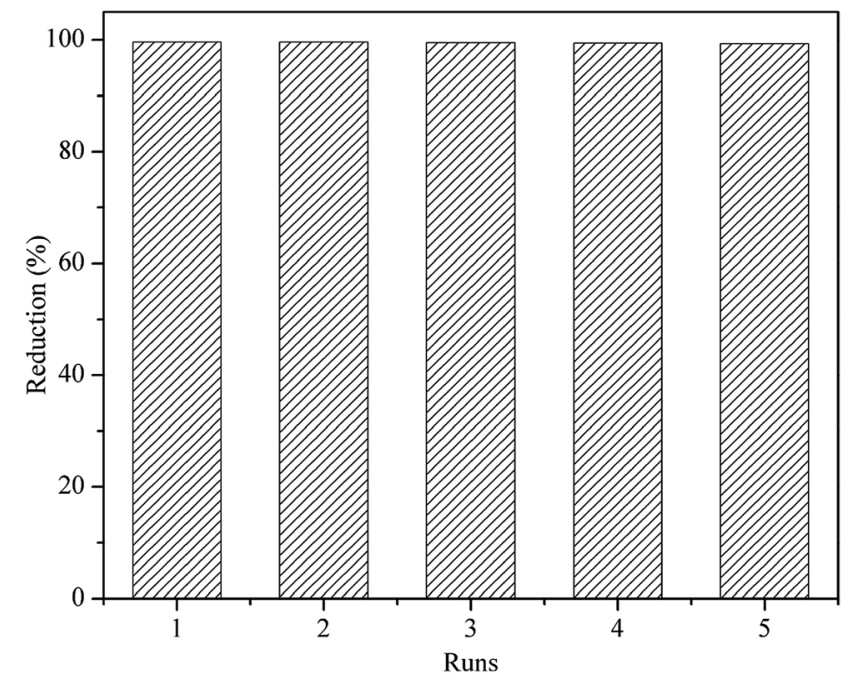

Fig. 10 The repetitive oxidation of PP-EPMn.
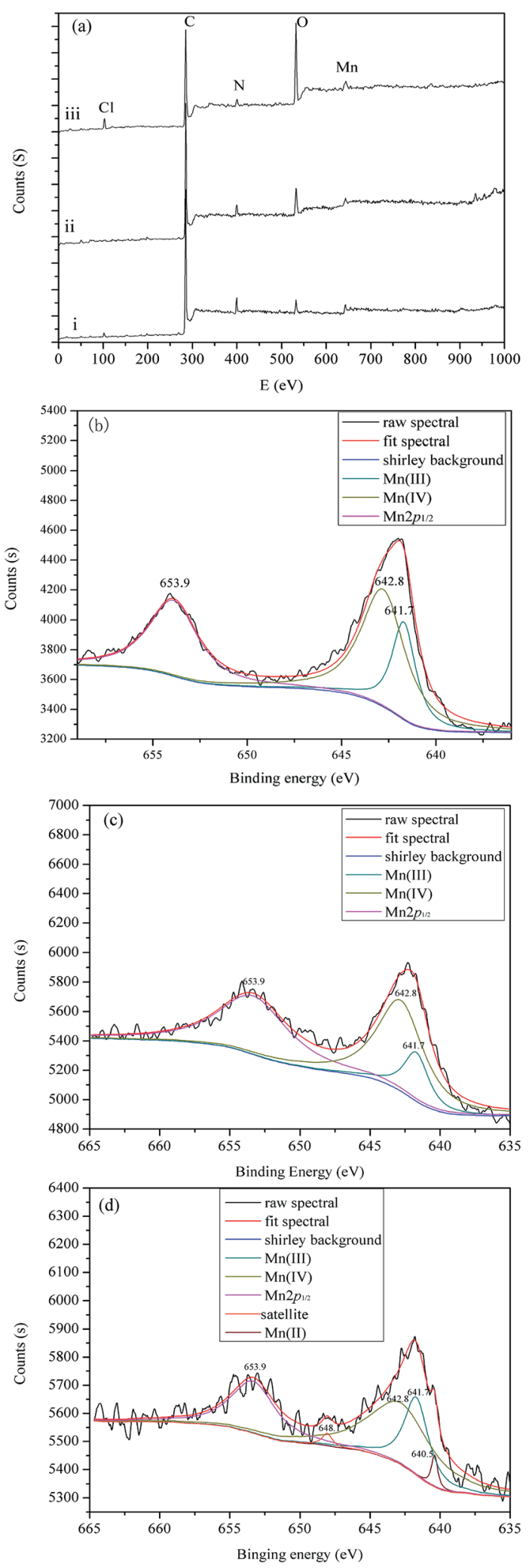

Fig. 11 XPS analysis of different samples. (a) XPS survey of [pethynyl $]_{4} P M n$ (i), PP-EPMn (ii) and used PP-EPMn (iii). (b) Decomposed XPS $M n 2 p$ binding energy spectrum of [p-ethynyl $]_{4} P M n$ catalyst. (c) Decomposed XPS Mn $2 p$ binding energy spectrum of PP-EPMn catalyst. (d) Decomposed XPS Mn 2p binding energy spectrum of used PP-EPMn catalyst. 
Table 3 The ratio analysis of the peaks in XPS spectra of the catalysts

\begin{tabular}{llcccc}
\hline & \multicolumn{7}{l}{ Atomic composition (at\%) } \\
\cline { 2 - 6 } Catalysts & $\mathrm{C}$ & $\mathrm{O}$ & $\mathrm{N}$ & $\mathrm{Cl}$ & $\mathrm{Mn}$ \\
\hline [p-Ethynyl] ${ }_{4} \mathrm{PMn}$ & 88.94 & 3.61 & 4.87 & 1.38 & 1.2 \\
PP-EPMn & 84.41 & 9.02 & 4.61 & 0.82 & 1.14 \\
PP-EPMn used & 80.55 & 13.3 & 4.54 & 0.51 & 1.1
\end{tabular}

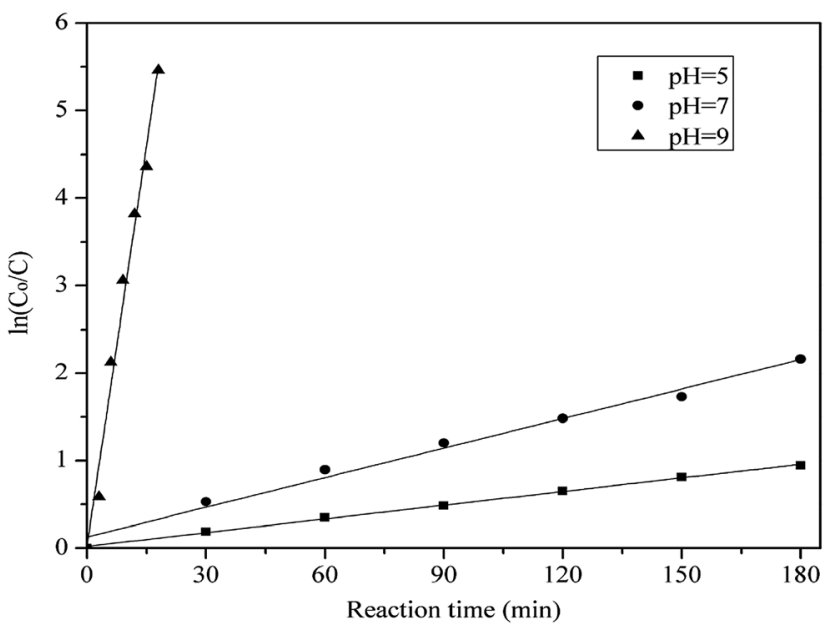

Fig. $12 \ln \left(C_{0} / C\right)$ versus reaction time for the reduction of methylene blue in the presence of PP-EPMn at $\mathrm{pH}=5,7,9 . \mathrm{C}_{\mathrm{o}}$ and $\mathrm{C}$ are the initial and transient concentrations of methylene blue during the reaction, respectively. Reaction conditions: methylene blue, $50 \mathrm{~mL}\left(10 \mathrm{mg} \mathrm{L}^{-1}\right)$; catalyst, 4 mg PP-EPMn; $\mathrm{H}_{2} \mathrm{O}_{2} ; T=25^{\circ} \mathrm{C}$.

relationship between the concentration variation of methylene blue $\left(\ln \left(C_{\mathrm{o}} / C\right)\right)$ and the reaction time $(t)$ was shown in Fig. 12. It was found that the kinetic model was corresponded to the pseudo-first order at different $\mathrm{pH}$ values. The reaction rate constants can be calculated by the following equation, where $k$ is the apparent rate constant at different $\mathrm{pH}$ values.

$$
\ln \left(C_{\mathrm{o}} / C\right)=k t
$$

When $\mathrm{pH}=5,7,9$, the value of $k$ was calculated as $4.26 \times$ $10^{-3} \mathrm{~min}^{-1}, 1.14 \times 10^{-2} \mathrm{~min}^{-1}, 0.308 \mathrm{~min}^{-1}$, respectively. So PP-EPMn had higher degradation efficiency under alkaline condition $(\mathrm{pH}=\geq 7)$.

\subsection{Plausible reaction mechanism}

The efficiency of methylene blue decomposition is determined by two competitive processes of hydrogen peroxide cleavages, i.e. heterolytic and homolytic cleavages of $-\mathrm{O}-\mathrm{O}-$ bond in manganese(III)-coordinated hydrogen peroxide molecule. ${ }^{37,40}$ The former process produces a ${ }^{\circ} \mathrm{OH}$ radical, while the latter process generates a oxomanganese(v) porphyrin intermediate which is active for methylene blue decomposition. ${ }^{39}$ The main oxidative species in catalytic process can be detected through radical trapping experiments. As shown in Fig. 13b, when adding isopropanol, a scavenger of hydroxyl radicals, ${ }^{41}$ little changes were found at $\mathrm{pH}=9$. However, the catalytic activity of PP-EPMn was greatly inhibited at $\mathrm{pH}=5$ (Fig. 13a). Accordingly, $\cdot \mathrm{OH}$ radical would be the main active species at $\mathrm{pH}=5$, while the oxomanganese(v) porphyrin intermediate was the main active and more efficient species at $\mathrm{pH}=9$.

Since methylene blue was completely degraded in a short time in alkaline solution but only partly degraded in a long time in acidic solution, apparently the -O-O- bond cleavage of hydro peroxides was sensitive to the $\mathrm{pH}$ of the reaction solution. So we postulated that the -O-O- bond cleavage of $\mathrm{H}_{2} \mathrm{O}_{2}$ depended on $\mathrm{pH}$ of the reaction solution. -O-O- bond homolysis prevailed at low $\mathrm{pH}$ and -O-O- bond heterolysis became predominant at

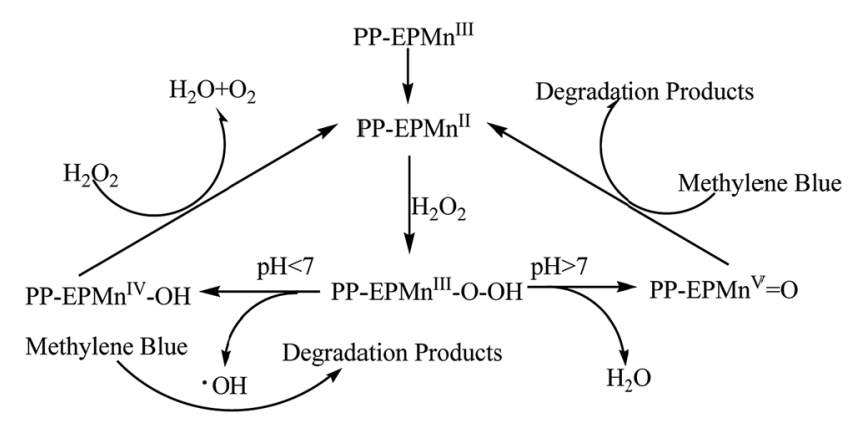

Scheme 2 The plausible reaction mechanism.
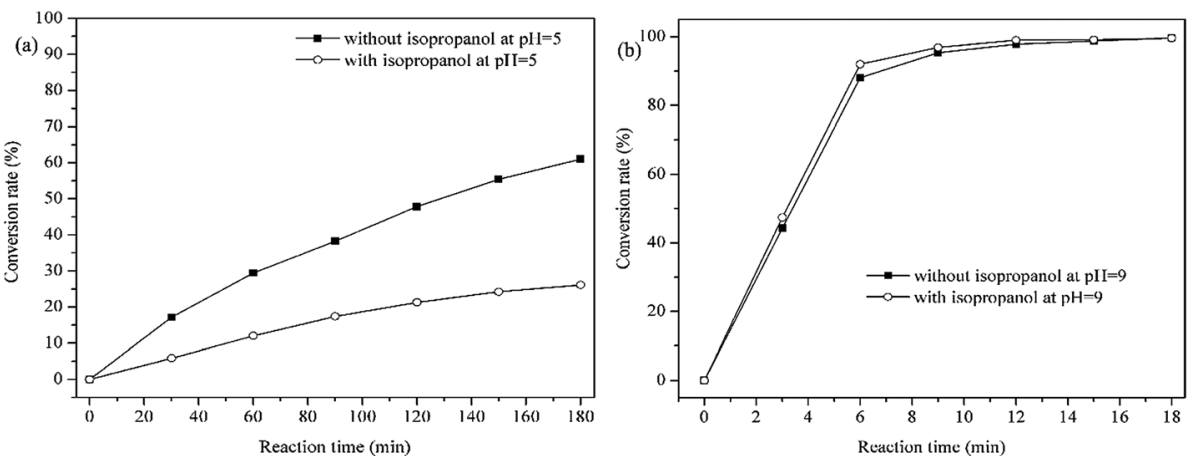

Fig. 13 Concentration changes of methylene blue in the presence or without isopropanol at $\mathrm{pH}=5$ and $\mathrm{pH}=9$. Reaction conditions: methylene blue, $50 \mathrm{~mL}\left(10 \mathrm{mg} \mathrm{L}^{-1}\right)$; catalyst, $4 \mathrm{mg} \mathrm{PP}-\mathrm{EPMn} ; \mathrm{H}_{2} \mathrm{O}_{2} ; \mathrm{T}=25^{\circ} \mathrm{C}$. 
high $\mathrm{pH}$. The plausible reaction mechanism is shown in Scheme 2.

In acidic condition, the homolytic cleavage of -O-O- bond in PP-EPMn ${ }^{\mathrm{III}}-\mathrm{OOH}$ produces a ${ }^{\circ} \mathrm{OH}$ radical, but $\mathrm{PP}-\mathrm{EPMn}^{\mathrm{IV}}-\mathrm{OH}$ with a lower activity can decompose $\mathrm{H}_{2} \mathrm{O}_{2}$ simultaneously, so methylene blue decomposed slowly and partly. In alkaline solution, however, the heterolytic cleavage of -O-O- bond in PP$\mathrm{EPMn}^{\mathrm{III}}$-OOH generates an oxomanganese(v) porphyrin intermediate that is active for methylene blue decomposition. As a result, methylene blue was better degraded in alkaline condition.

\section{Conclusions}

Nanospheres of organic conjugated metalloporphyrin polymers (PP-EPMn and PX-EPMn) were synthesized with [p-ethynyl $]_{4^{-}}$ PMn as building block and with phenylene or xenyl groups as bridges for the first time. PP-EPMn and PX-EPMn both had special nanosphere structures and PP-EPMn nanospheres had diameters of 200-400 nm, but PX-EPMn ones had a more uniform diameter of $150 \mathrm{~nm}$. Methylene blue solution was chosen as a model of typical dye-containing wastewater. PPEPMn and PX-EPMn were applied as catalysts to degrade methylene blue in aqueous solution. The effects of temperature, amount of catalyst, $\mathrm{pH}$ and amount of hydrogen peroxidate were assessed in detail (ESI $\dagger$ ). Both PP-EPMn and PX-EPMn showed high catalytic efficiencies against methylene blue pollutant through degradation. The two polymers applicable to alkaline wastewater treatment were superior to Fenton reagents which only worked in acidic condition. PP-EPMn and PX-EPMn can be recycled and continuously used, thereby being potentially suitable for industrial methylene blue removal.

\section{Conflicts of interest}

There are no conflicts to declare.

\section{Acknowledgements}

The authors would like to give thanks for the financial support from the National Nature Science Foundation of China (Grant No. 21576074). The authors are also grateful for the financial support of Hunan University.

\section{References}

1 S. Durot, J. Taesch and V. Heitz, Chem. Rev., 2014, 114, 85428578.

2 Q. C. Dong, W. S. Qu, W. Q. Liang, F. F. Tai, K. P. Guo, C. W. Leung, Y. H. Lo and W. Y. Wong, Mater. Chem., 2016, 4, 5010-5018.

3 S. Mathew, A. Yella, P. Gao, R. Humphry-Baker, B. F. E. Curchod, N. Ashari-Astani, I. Tavernelli, U. Rothlisberger, M. K. Nazeeruddin and M. Grätzel, Nat. Chem., 2014, 6, 242-247.
4 A. D'Urso, A. Mammana, M. Balaz, A. E. Holmes, N. Berova, R. Lauceri and R. Purrello, J. Am. Chem. Soc., 2009, 131, 20462047.

5 M. G. Rabbani, A. K. Sekizkardes, Z. Kahveci, T. E. Reich, R. S. Ding and H. M. A. El-Kaderi, Chem.-Eur. J., 2013, 19, 3324-3328.

6 H. M. Key, P. Dydio, D. S. Clark and J. F. Hartwig, Nature, 2016, 534, 534-537.

7 G. Labut, J. L. Seris and B. Meunier, Angew. Chem., Int. Ed. Engl., 1990, 29, 1471-1473.

8 Q. Q. Zhu, M. Igarashi, M. Sasaki, T. Miyamoto, R. Kodama and M. Fukushima, Appl. Catal., B, 2016, 183, 61-68.

9 C. L. Hill and R. B. Brown, J. Am. Chem. Soc., 1986, 108, 536538.

10 I. Dror and M. A. Schlautman, Environ. Toxicol. Chem., 2004, 23, 252-257.

11 W. J. Yang, B. J. Yin, C. C. Guo, Z. Tan and L. Zhang, Chin. J. Catal., 2010, 31, 535-540.

12 Q. Y. Liu, R. R. Zhu, Y. L. Jiang, Q. Y. Jia, S. G. Yang, Q. Shao, D. M. Wang and P. Cui, Mater. Sci. Eng., B, 2014, 188, 106113.

13 K. Kalyanasundaram, Inorg. Chem., 1984, 23, 2453-2459.

14 M. A. Martí, S. E. Bari, D. A. Estrin and F. Doctorovich, J. Am. Chem. Soc., 2005, 127, 4680-4684.

15 C. Crestini, R. Saladino, P. Tagliatesta and T. Boschi, Bioorg. Med. Chem., 1999, 7, 1897-1905.

16 A. Rezaeifard and M. Jafarpour, Catal. Sci. Technol., 2014, 4, 1960-1969.

17 H. Kim, W. Kim, Y. Mackeyev, G. S. Lee, H. J. Kim, T. Tachikawa, S. k. Hong, S. Lee, J. B. Kim, L. J. Wilson, T. Majima, P. J. J. Alvarez, W. Y. Choi and J. S. Lee, Environ. Sci. Technol., 2012, 46, 9606-9613.

18 H. Ghafuri, S. Rahmani, R. Rahimi and E. Mohammadiyan, RSC Adv., 2016, 6, 62916-62922.

19 M. Moshari, M. Rabbani and R. Rahimi, Res. Chem. Intermed., 2016, 42, 5441-5455.

20 M. Wei, J. Wan, Z. W. Hu, Z. Q. Peng and B. Wang, Appl. Surf. Sci., 2016, 377, 149-158.

21 C. Wang, J. Li, G. Mele, G. M Yang, F. X. Zhang, L. Palmisano and G. Vasapollo, Appl. Catal., B, 2007, 76, 218-226.

22 J. Yoo, N. Park, J. H. Park, J. H. Park, S. Kang, S. M. Lee, H. J. Kim, H. Jo, J. G. Park and S. U. Son, ACS Catal., 2015, 5, 350-355.

23 Y. H. Jiang, L. Q. Guo, W. L. Zhang, F. Dai, Y. Yan, F. M. Zhang and H. Y. Lv, Desalin. Water Treat., 2014, 52, 3489-3496.

24 X. Guo, Y. Y. Li, D. H. Shen, J. Gan, M. Tian, Z. Gang and Z. G. Liu, Appl. Catal., A, 2012, 413-414, 30-35.

25 W. J. Yang, C. C. Guo, Z. Y. Li and N. Y. Tao, J. Porphyrins Phthalocyanines, 2009, 13, 973-979.

26 Y. J. Li, B. S. Sun and W. J. Yang, Appl. Catal., A, 2016, 515, 164-169.

27 L. Chen, Y. Yang and D. L. Jiang, J. Am. Chem. Soc., 2010, 132, 9138-9143.

28 A. I. Cooper, Adv. Mater., 2009, 21, 1291-1295.

29 Y. J. Li, C. R. Liu and W. J. Yang, New J. Chem., 2017, 41, 8214-8221. 
30 J. H. Zhu, Z. W. Tan and W. J. Yang, Macromol. Res., 2017, 25, 792-798.

31 Z. W. Tan, J. H. Zhu and W. J. Yang, Catal. Commun., 2017, 94, 60-64.

32 Y. J. Li, B. S. Sun, Y. Y. Zhou and W. J. Yang, Appl. Organomet. Chem., 2017, 31, 170-176.

33 K. Ladomenou, V. Nikolaou, G. Charalambidis and A. G. Coutsolelos, Coord. Chem. Rev., 2016, 306, 1-42.

34 J. S. Hsiao, B. P. Krueger, R. W. Wagner, T. E. Johnson, J. K. Delaney, D. C. Mauzerall, G. R. Fleming, J. S. Lindsey, D. F. Bocian and R. J. Donohoe, J. Am. Chem. Soc., 1996, 118, 11181-11191.

35 R. W. Wagner, T. E. Johnson and J. S. Lindsey, J. Am. Chem. Soc., 1996, 118, 11166-11180.
36 Q. Sun, B. Aguila, G. Verma, X. J. Meng, F. S. Xiao and S. Q. Ma, Chem, 2016, 1, 628-639.

37 W. J. Zhang, P. P. Jiang, Y. Wang, J. Zhang and P. B. Zhang, Catal. Sci. Technol., 2015, 5, 101-104.

38 C. C. Guo, M. F. Chu, Q. Liu, Y. Liu, D. C. Guo and X. Q. Liu, Appl. Catal., A, 2003, 246, 303-309.

39 W. W. Nam, I. Kim, M. H. Lim, H. J. Choi, J. S. Lee and H. G. Jang, Chem.-Eur. J., 2002, 8, 2067-2071.

40 W. W. Nam, H. J. Choi, H. J. Han, S. H. Cho, H. J. Lee and S. Y. Han, Chem. Commun., 1999, 4, 387-388.

41 C. Minero, G. Mariella, V. Maurino, D. Vione and E. Pelizzetti, Langmuir, 2000, 16, 8964-8972. 